\title{
In vitro antiviral activity of medicinal mushroom Ganoderma neo-japonicum Imazeki against enteroviruses that caused hand, foot and mouth disease
}

\author{
Ang, W.X. ${ }^{1}$, Sarasvathy, S. ${ }^{1,2}$, Kuppusamy, U.R. ${ }^{1,2}$, Sabaratnam, V. $^{2}$, Tan, S.H. ${ }^{1}$, Wong, K.T. ${ }^{3}$, Perera, D. ${ }^{4}$, \\ Ong, K.C. ${ }^{1 *}$
}

${ }^{1}$ Department of Biomedical Science, Faculty of Medicine, University of Malaya, Kuala Lumpur, Malaysia

${ }^{2}$ Mushroom Research Centre, Institute of Biological Sciences, Faculty of Science, University of Malaya, Kuala Lumpur, Malaysia

${ }^{3}$ Department of Pathology, Faculty of Medicine, University of Malaya, Kuala Lumpur, Malaysia

${ }^{4}$ Institute of Health and Community Medicine, Universiti Malaysia Sarawak, Kota Samarahan, Sarawak, Malaysia

*Corresponding author: kcong@um.edu.my

\section{ARTICLE HISTORY}

Received: 16 April 2021

Revised: 29 May 2021

Accepted: 30 May 2021

Published: 31 July 2021

\begin{abstract}
Hand, foot and mouth disease (HFMD) is a highly contagious viral disease that predominantly affects children younger than 5 years old. HFMD is primarily caused by enterovirus A71 (EVA71) and coxsackievirus A16 (CV-A16). However, coxsackievirus A10 (CV-A10) and coxsackievirus A6 (CV-A6) are being increasingly reported as the predominant causative of HFMD outbreaks worldwide since the past decade. To date, there are still no licensed multivalent vaccines or antiviral drugs targeting enteroviruses that cause HFMD, despite HFMD outbreaks are still being frequently reported, especially in Asia-Pacific countries. The high rate of transmission, morbidity and potential neurological complications of HFMD is indeed making the development of broad-spectrum antiviral drugs/agents against these enteroviruses a compelling need. In this study, we have investigated the in vitro antiviral effect of 4 Ganoderma neo-japonicum Imazeki (GNJI) crude extracts (S1-S4) against EV-A71, CV-A16, CV-A10 and CV-A6. GNJI is a medicinal mushroom that can be found growing saprophytically on decaying bamboo clumps in Malaysian forests. The antiviral effects of this medicinal mushroom were determined using cytopathic inhibition and virus titration assays. The $\mathrm{S} 2(1.25 \mathrm{mg} / \mathrm{ml})$ hot aqueous extract demonstrated the highest broad-spectrum antiviral activity against all tested enteroviruses in human primary oral fibroblast cells. Replication of EV-A71, CV-A16 and CVA10 were effectively inhibited at 2 hours post-infection (hpi) to $72 \mathrm{hpi}$, except for CV-A6 which was only at $2 \mathrm{hpi}$. S2 also has virucidal activity against EV-A71. Polysaccharides isolated and purified from crude hot aqueous extract demonstrated similar antiviral activity as S2, suggesting that polysaccharides could be one of the active compounds responsible for the antiviral activity shown by S2. To our knowledge, this study demonstrates for the first time the ability of GNJI to inhibit enterovirus infection and replication. Thus, GNJI is potential to be further developed as an antiviral agent against enteroviruses that caused HFMD.
\end{abstract}

Keywords: Antiviral; enteroviruses; Ganoderma neo-japonicum Imazeki; hand, foot and mouth disease.

\section{INTRODUCTION}

Hand, foot and mouth disease (HFMD) is a common pediatric infectious disease caused by Enterovirus A species (EV-A) within the family of Picornaviridae. Enteroviruses are nonenveloped and positive-sense single-stranded RNA viruses (Linden et al., 2015). Enterovirus A71 (EV-A71) and coxsackievirus A16 (CV-A16) are the most prevalent etiological pathogens for HFMD (Klein \& Chong, 2015). However, CV-A10 and $\mathrm{CV}-\mathrm{A} 6$ are rapidly emerging and being increasingly reported to cause HFMD outbreaks worldwide such as in Finland (Blomqvist et al., 2010), Taiwan (Wei et al., 2011), Spain (Bracho et al., 2011), France (Mirand et al., 2012),
Edinburgh in the United Kingdom (Stewart et al., 2013), China (Chen et al., 2017; Bian et al., 2019), Vietnam (Anh et al., 2018), Argentina (Cisterna et al., 2019), Belem in Northern Brazil (Justino et al., 2020) and Uruguay (Lizasoain et al., 2020). Children under the age of 5 are the most susceptible and vulnerable groups for HFMD. Although rare, infections with EV-A71 can be associated with severe central nervous system (CNS) complications (Lei et al., 2015). In contrast, CV-A16, CVA10 and CV-A6 associated HFMD are usually self-limited with symptoms such as fever, mouth ulcers and skin rashes on palms and/or soles of the feet (Repass et al., 2014). HFMD is highly contagious and easily transmitted from person-toperson via oral-oral and/or fecal-oral routes (Klein \& Chong, 
2015). Large HFMD outbreaks have been reported worldwide and more recently from countries within the West Pacific region including Malaysia, Singapore, Japan and China (Wu et al., 2010; Liu et al., 2014), causing severe healthcare burden and disruption.

To date, broad-spectrum antiviral drugs against the enteroviruses that caused HFMD are not available. Despite three EV-A71 inactivated vaccines are currently licensed and used in China (Lin et al., 2019), these vaccines only confer protection against EV-A71 but not other enteroviruses (Tan \& Chu, 2017; Lin et al., 2019). Hence, having broad-spectrum antiviral agents to control the disease transmission and complications is desirable.

In the past decade, Ganoderma mushrooms have been reported as one of the best-known medicinal fungus species with a wide range of medicinal properties, including antiviral, anti-cancer, anti-inflammatory and immunomodulatory properties (Sliva, 2003; Li et al., 2006; Baby et al., 2015; Hapuarachchi et al., 2017). G.lucidum and G.tsugae are the 2 most extensively investigated Ganoderma species thus far (Ferreira et al., 2015; Huang et al., 2019). In contrast, the medicinal properties of G.neo-japonicum Imazeki (GNJI) which can be found growing saprophytically on decaying bamboo (Schizostachyum brachyladium) clumps in the forests of several countries including Malaysia, Japan, China, Korea and Taiwan, are yet to be fully explored (Tan et al., 2015; Subramaniam et al., 2017; Subramaniam et al., 2020). Its antiviral properties are still unknown as compared to $G$. lucidum (Tan et al., 2015).

In this study, we have demonstrated that GNJI crude aqueous extract exerted potent and broad-spectrum in vitro antiviral activity against EV-A71, CV-A16, CV-A10 and CV-A6 infection in human primary oral fibroblast cells. Polysaccharides could be one of the active antiviral compounds responsible for the antiviral activities demonstrated in this study. These highlighted the great potential of this medicinal mushroom to be further developed into a broad-spectrum antiviral agent against enteroviruses that caused HFMD and perhaps other viruses as well.

\section{MATERIALS AND METHODS}

\section{Cells and viruses}

Human primary oral fibroblast (HPOF) cells used in this study were previously isolated from the lip mucosa of a 3-month old infant (Phyu et al., 2017). The cells were grown and maintained in Dulbecco's Modified Eagle's Medium (DMEM) (Sigma-Aldrich, USA) with Ham's F-12 Nutrient Mixture (F12) (Sigma-Aldrich, USA) in a ratio of 1:1 (DMEM/F12), supplemented with $10 \%$ fetal bovine serum (FBS) (Hyclone, USA) and $1 \mathrm{ng} / \mathrm{ml}$ fibroblast growth factor (Promega, USA). African green monkey kidney (Vero) cells were grown in DMEM growth medium (DMEM-GM) supplemented with 5\% FBS and human rhabdomyosarcoma (RD) cells in DMEM-GM supplemented with 5\% FBS and 5\% horse serum (HS) (Gibco, USA). EV-A71, CV-A16, CV-A10 and CV-A6 used in this study were previously isolated from children with HFMD. To prepare virus stocks, EV-A71 and CV-A16 were propagated in Vero cells with DMEM maintenance medium (DMEM-MM) supplemented with $2 \%$ FBS, and CV-A10 and CV-A6 in RD cells with DMEM-MM supplemented with $2 \% \mathrm{FBS}$ and $2 \% \mathrm{HS}$. The virus titer was determined using a $50 \%$ cell culture infective dose $\left(C C I D_{50}\right)$ assay in Vero or RD cells as described previously (Ong et al., 2008).

\section{Mushroom extract preparation}

GNJI extract powder was prepared as described previously (Subramaniam et al., 2017). A total of 5 extracts (S1-S5) were tested in this study. S1 and S2 were crude hot aqueous extracts obtained with 30 mins and 3 hours boiling, respectively, whereas S3 and S4 were $70 \%$ and $100 \%$ crude ethanolic extracts, respectively. S5 was the GNJI polysaccharides fraction isolated and purified from the crude aqueous extract with 4 hours of boiling. The S1, S2, S3 and S5 powder were dissolved in DMEM to a final concentration of $10 \mathrm{mg} / \mathrm{ml}$, whereas S4 powder was dissolved in dimethyl sulfoxide (DMSO) (Sigma-Aldrich, USA) to a final concentration of $25 \mathrm{mg} / \mathrm{ml}$. The solutions were filtered through a 0.22 $\mu \mathrm{m}$ pore-size filter (Sartorius, Minisart, Germany), aliquoted and stored at $-20^{\circ} \mathrm{C}$ before use.

\section{Virus titration}

$50 \%$ cell culture infectious dose $\left(\mathrm{CCID}_{50}\right)$ assay was performed as described previously (Ong et al., 2008). Briefly, Vero or RD cells were seeded in a 96 -well plate overnight at $37^{\circ} \mathrm{C}$. Tenfold serial dilutions of the virus supernatant $\left(10^{-1}\right.$ to $\left.10^{-8}\right)$ in DMEM-MM were prepared and $100 \mu$ of each dilution was inoculated at quadruplicate. The plate was then further incubated for 5 days. $\mathrm{CCID}_{50}$ was calculated using the Spearman-Karber method (Karber, 1931).

\section{Determination of maximal non-toxic dose (MNTD)}

The maximal non-toxic dose (MNTD) of each crude extract (S1-S4) was determined using Cell Titre $96^{\circ}$ Aqueous One Solution Cell Proliferation Assay (MTS) (Promega, USA) and cell morphological observation. MTS assay was performed according to the manufacturer's instructions. Briefly, HPOF cells were seeded in a 96-well plate at cell density of $1.5 \times 10^{4}$ cells/well before incubating with different concentrations of S1, S2, S3 $(0.078 \mathrm{mg} / \mathrm{ml}$ to $2.5 \mathrm{mg} / \mathrm{ml})$, S4 $(0.003 \mathrm{mg} / \mathrm{ml}$ to 0.1 $\mathrm{mg} / \mathrm{ml}$ ), DMSO (diluent for $\mathrm{S} 4,0.013 \%$ to $0.4 \%$ ) or DMEM (negative control) in quadruplicate. Cells were observed daily for any morphological changes under an inverted microscope. After incubation for 3 days at $37^{\circ} \mathrm{C}$, the optical density (OD) in each well was measured using a microplate reader (PowerWave X340, BioTek, USA) at $490 \mathrm{~nm}$ wavelength with a reference wavelength of $600 \mathrm{~nm}$. The $O D$ reading is directly proportional to the number of viable cells in the culture. The cell viability graph was presented as percentage of HPOF cells viability against extracts of different concentrations.

\section{Antiviral screening}

Non-toxic doses (NTD) of each crude extract (S1-S4) were first screened on EV-A71 using CPE inhibition assay. Extracts that demonstrated complete inhibition of EV-A71 CPE were then selected and tested on CV-A16. Only the extracts that demonstrated $100 \%$ CPE inhibition for both viruses were chosen for final testing on CV-A10 and CV-A6. Briefly, HPOF cells were pre-seeded at $1.5 \times 10^{4}$ cells/well in a 48 -well plate overnight at $37^{\circ} \mathrm{C}$ before incubated with the NTD of each extract for 24 hours at $37^{\circ} \mathrm{C}$. The next day, the pre-treated cells were inoculated with $100 \mathrm{CClD}_{50}$ of the virus and incubated for 5 days at $37^{\circ} \mathrm{C}$. Untreated, virus inoculated cells were served as virus positive controls while treated and mock-inoculated cells were served as negative cells controls.

\section{In vitro antiviral experiments}

Since S2 extract $(1.25 \mathrm{mg} / \mathrm{ml})$ demonstrated the most broadspectrum antiviral activity against all 4 tested enteroviruses, the in vitro antiviral activities were further investigated by pre-infection treatment, post-infection treatment and virucidal experiments. All 3 experiments were performed simultaneously in a 96 well-plate with a cell-density of $1.5 \times 10^{4}$ cells/well. The other extracts were not studied further. 


\section{i. Pre-infection treatment experiment}

Briefly, HPOF cells were pre-treated with $1.25 \mathrm{mg} / \mathrm{ml}$ of S2 overnight (approximately $24 \mathrm{hrs}$ ) at $37^{\circ} \mathrm{C}$. After overnight incubation, treated and untreated cells were washed twice with PBS before infecting with $100 \mathrm{CCID}_{50}$ of virus. Following pre-absorption for 2 hours at $37^{\circ} \mathrm{C}$, unbound viruses were removed, and the cells were washed twice with PBS before replacing with new DMEM/F12 medium. Infected and uninfected cells were observed daily. At 5 days post-infection (dpi), the plate was freeze-thawed 3 times and viral-titrated using the $\mathrm{CCID}_{50}$ assay as described.

\section{ii. Post-infection treatment experiment}

HPOF cells were infected with $100 \mathrm{CCID}_{50}$ of virus for 2 hours at $37^{\circ} \mathrm{C}$. Infected cells were then washed twice with PBS before treated with $1.25 \mathrm{mg} / \mathrm{ml}$ of S2. Treated and untreated cells were observed daily. At $5 \mathrm{dpi}$, the plate was freeze-thawed and viral-titrated as described.

\section{iii. Virucidal experiment}

An equal volume of S2 $(2.5 \mathrm{mg} / \mathrm{ml})$ was mixed with $200 \mathrm{CCID}_{50}$ of virus and incubated for 1 hour at $37^{\circ} \mathrm{C}$. The mixtures were then added onto the HPOF cells and further incubated for 2 hours at $37^{\circ} \mathrm{C}$ for virus pre-absorption. The virus-S2 mixture was then removed and the cells were washed twice with PBS before replacing with new DMEM/F12 medium. Cells inoculated with virus-S2, virus-DMEM/F12 and DMEM-DMEM/ F12 mixtures, respectively, were observed daily. At $5 \mathrm{dpi}$, the plate was freeze-thawed and viral-titrated as described.

\section{Determination of the post-infection treatment efficacy of S2}

To evaluate the efficacy of $\mathrm{S} 2$ in inhibiting intracellular virus replication, HPOF cells were seeded and infected as described in the post-infection treatment experiment, except with an $\mathrm{MOI}$ of 0.01 . Infected cells were treated with $1.25 \mathrm{mg} /$ $\mathrm{ml}$ of S2 at 2, 24, 48, or 72 hours post-infection (hpi). At $5 \mathrm{dpi}$, the plate was freeze-thawed and viral-titrated as described.
Determination of the antiviral activity of GNJ polysaccharides To determine if polysaccharides isolated from hot aqueous extracts could contribute to the observed S2 antiviral effects, the polysaccharides (S5) (Subramaniam et al., 2017) were tested for their antiviral activity against EV-A71 and CV-A16 as described in the post-infection treatment experiment. S5 was also tested for virucidal activity against EV-A71 as described in the virucidal experiment. Briefly, for the postinfection treatment experiment, HPOF cells were seeded and infected with EV-A71 or CV-A16 at MOI of 0.01 as described. Infected cells were treated with $1.25 \mathrm{mg} / \mathrm{ml}$ of S5 at 2, 24, 48 and $72 \mathrm{hpi}$. For the virucidal experiment, EV-A71 $\left(2 \times 10^{3} \mathrm{CCID}_{50}\right)$ was incubated with an equal volume of $\mathrm{S} 5(2.5 \mathrm{mg} / \mathrm{ml})$ for 1 $\mathrm{hr}$ at $37^{\circ} \mathrm{C}$. The virus-S5 mixture was then added onto the HPOF for virus pre-absorption for $2 \mathrm{hrs}$ at $37^{\circ} \mathrm{C}$. Uninfected cells treated with $1.25 \mathrm{mg} / \mathrm{ml}$ of $\mathrm{S} 5$ were set up for cytotoxicity assessment. At $5 \mathrm{dpi}$, the plate was freeze-thawed and viraltitrated as described.

\section{Statistical analysis}

Data were expressed as mean \pm standard deviation (SD). All statistical analyses were performed using the MaxStat Lite Statistic Software (MaxStat, Germany). As data were normally distributed (Anderson-Darling Normality Test), a two-tailed unpaired t-test was used to determine the statistical significance between treated and untreated cells. A pvalue $<0.05$ was considered statistically significant.

\section{RESULTS}

\section{Determination of maximal non-toxic dose (MNTD)}

Based on the MTS (Figure 1 ) and cell morphology results, S1 ( $0.078 \mathrm{mg} / \mathrm{ml}$ to $0.625 \mathrm{mg} / \mathrm{ml}), \mathrm{S} 2(0.078 \mathrm{mg} / \mathrm{ml}$ to $1.25 \mathrm{mg} / \mathrm{ml})$, S3 $(0.078 \mathrm{mg} / \mathrm{ml}$ to $0.625 \mathrm{mg} / \mathrm{ml})$ and $\mathrm{S} 4(0.003 \mathrm{mg} / \mathrm{ml}$ to $0.025 \mathrm{mg} / \mathrm{ml}$ ) did not show a significant difference in cell viability ( $>90 \%$ viable) and cell morphology changes between inoculated and uninoculated cells. Therefore,

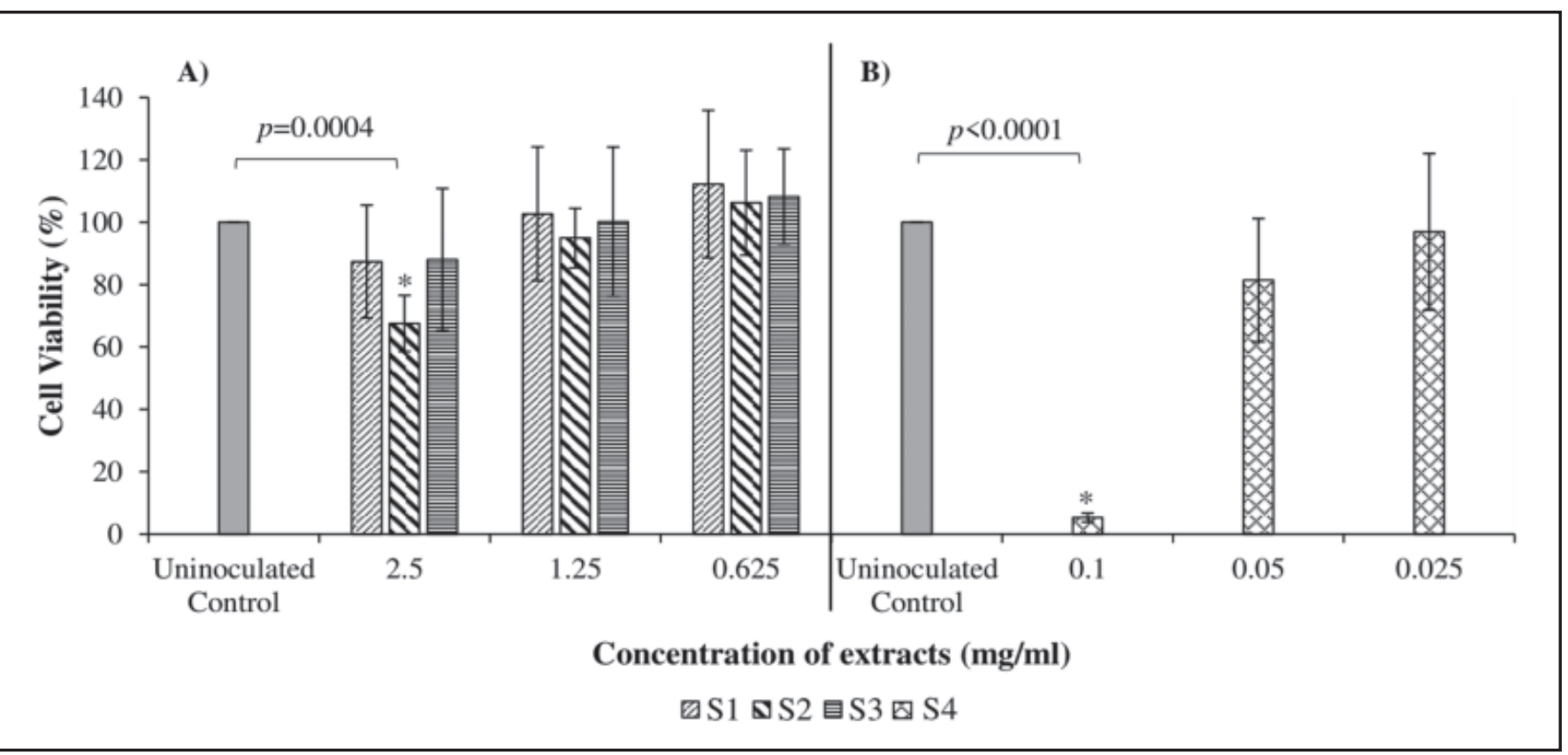

Figure 1. Human oral fibroblast cell viability after exposure to different concentrations of G.neo-japonicum Imazeki extracts. Percentage of cell viability determined by MTS assay after 3 days incubation with different concentrations of S1, S2 and S3 (A) and S4 (B). Concentrations lower than $0.625 \mathrm{mg} / \mathrm{ml}(\mathrm{A})$ and $0.025 \mathrm{mg} / \mathrm{ml}(\mathrm{B})$ are not displayed because the percentage of cell viability is not statistically significant compared to uninoculated control. The percentage of cell viability was expressed as mean percentage \pm standard deviation. ${ }^{*}=$ statistically significant $(p<0.05)$. 
these concentrations were selected and used for antiviral screening. DMSO present in S4 did not cause cytotoxicity to the cells.

\section{Antiviral screening}

MNTD of each crude extract demonstrated antiviral activity against EV-A71 with $100 \%$ CPE inhibition (Table 1). Since only the $1.25 \mathrm{mg} / \mathrm{ml}$ of $\mathrm{S} 2$ demonstrated $100 \%$ CPE inhibition for CV-A16 at the second screening, S2 $(1.25 \mathrm{mg} / \mathrm{ml})$ was selected for the final testing on CV-A10 and CV-A6. In contrast, $1.25 \mathrm{mg} /$ $\mathrm{ml}$ of $\mathrm{S} 2$ demonstrated moderate ( $60-70 \%)$ CPE inhibition in CV-A10 and CV-A6 infected cells (data not shown).

\section{In vitro antiviral activity}

In vitro antiviral activity of S2 $(1.25 \mathrm{mg} / \mathrm{ml})$ against all 4 viruses was investigated by performing pre-infection treatment, post-infection treatment and virucidal experiments. S2 did not demonstrate pre-infection treatment antiviral activity (Figure 2). In the post-infection treatment experiment, no virus was isolated in EV-A71 (Figure 2A) and CV-A16 (Figure 2B) infected cells. Meanwhile, the virus titers in CV-A10 (2.69 $\log _{10} \mathrm{CCID}_{50} \pm 0.515, p=0.0057$ ) (Figure 2C) and CV-A6 (3.06 $\log _{10}$ $\mathrm{CCID}_{50} \pm 0.125, p=0.01$ ) (Figure 2D) infected cells treated with S2 were significantly lower $(p<0.05)$ compared to the infected untreated controls $\left(4 \log _{10} \mathrm{CCID}_{50} \pm 0.354\right.$ and $3.56 \log _{10} \mathrm{CCID}_{50}$ \pm 0.239 , respectively).

S2 also demonstrated virucidal activity, but only against EV-A71 (Figure 2A). No virus was isolated in cells inoculated with EV-A71-S2 mixtures (Figure 2A). In contrast, virus titers were not significantly different in cells inoculated with CV-

Table 1. Antiviral screening of S1, S2, S3 and S4 against EV-A71 infection in human oral fibroblast cells

\begin{tabular}{|c|c|c|c|c|c|}
\hline \multirow{2}{*}{$\begin{array}{c}\begin{array}{c}\text { Mushroom } \\
\text { extracts }\end{array} \\
\text { S1 }\end{array}$} & \multicolumn{5}{|c|}{ Concentrations (mg/ml) } \\
\hline & 0.625 & 0.313 & 0.156 & 0.078 & \\
\hline & - & + & + & + & \\
\hline \multirow[t]{2}{*}{ S2 } & 1.25 & 0.625 & 0.313 & 0.156 & 0.078 \\
\hline & - & + & + & + & + \\
\hline \multirow[t]{2}{*}{ S3 } & 0.625 & 0.313 & 0.156 & 0.078 & \\
\hline & - & + & + & + & \\
\hline \multirow[t]{2}{*}{ S4 } & 0.025 & 0.013 & 0.006 & 0.003 & \\
\hline & - & + & + & + & \\
\hline
\end{tabular}

1) +: Presence of $C P E, 2)-:$ Absence of $C P E$.

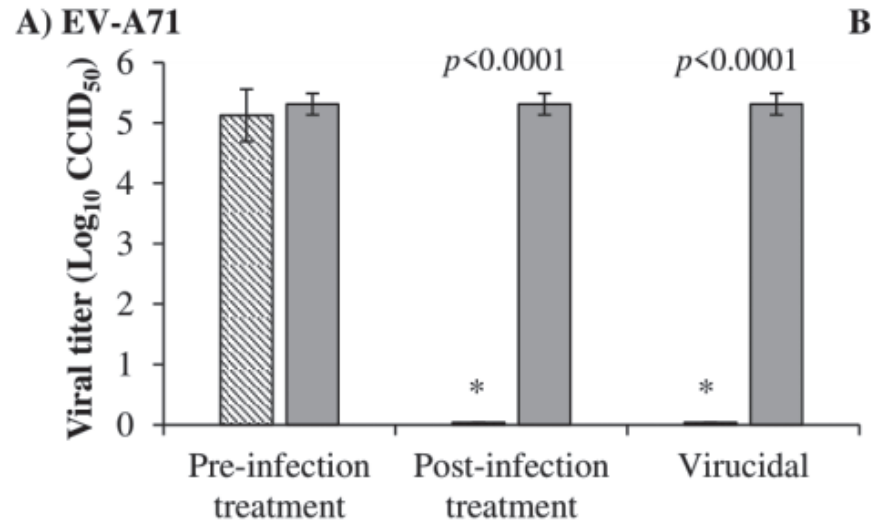

Antiviral experiments

C) CV-A10

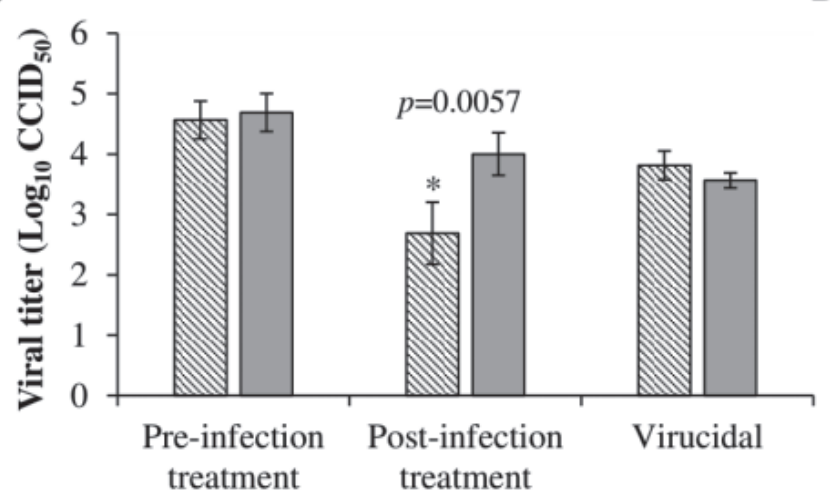

Antiviral experiments
B) CV-A16

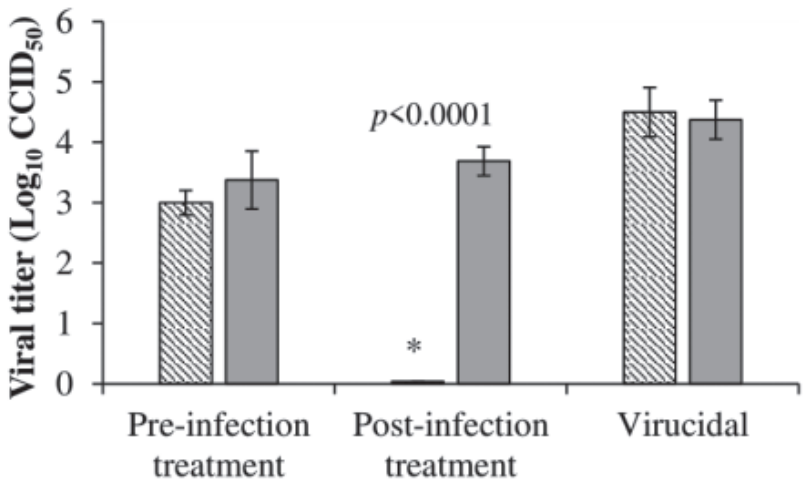

Antiviral experiments

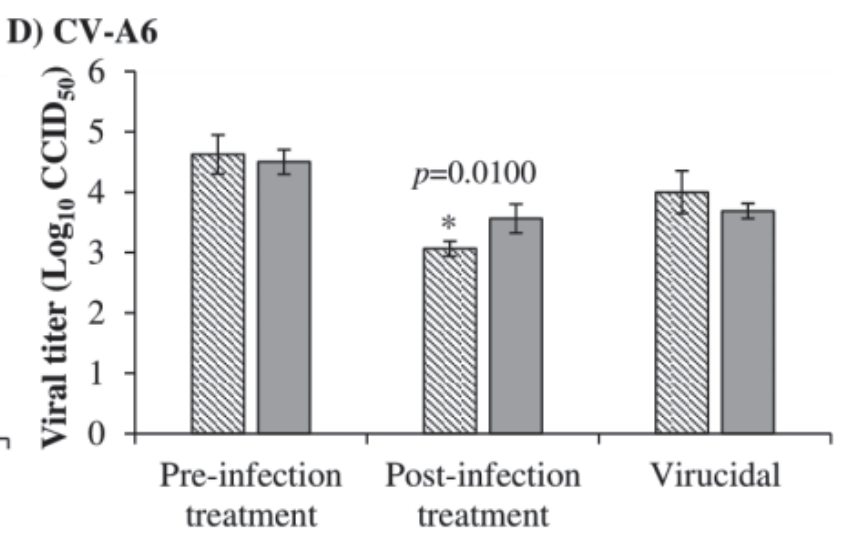

Antiviral experiments

\ Treated, Infected $\square$ Untreated, Infected

Figure 2. Viral titers of A) EV-A71, B) CV-A16, C) CV-A10 and D) CV-A6 in in vitro antiviral experiments. No antiviral activity was demonstrated in the pre-infection treatment experiment. The post-infection treatment experiment showed that $\mathrm{S} 2$ was able to inhibit replication of all viruses at $2 \mathrm{hpi}$. S2 only demonstrated virucidal activity against EV-A71 (A). Virus titers were expressed as the mean $\log _{10} \mathrm{CCID}_{50} \pm$ standard deviation. ${ }^{*}=$ statistically significant $(p<0.05)$. 
A) EV-A71

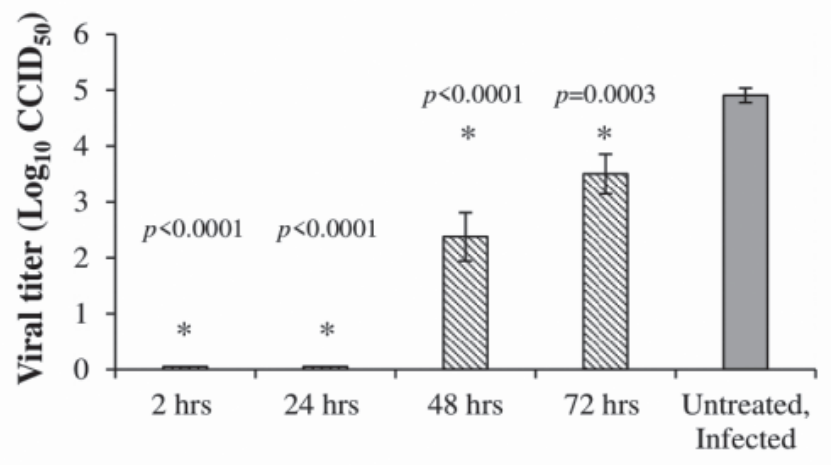

Treatment timepoint post-infection (hpi)
B) CV-A16

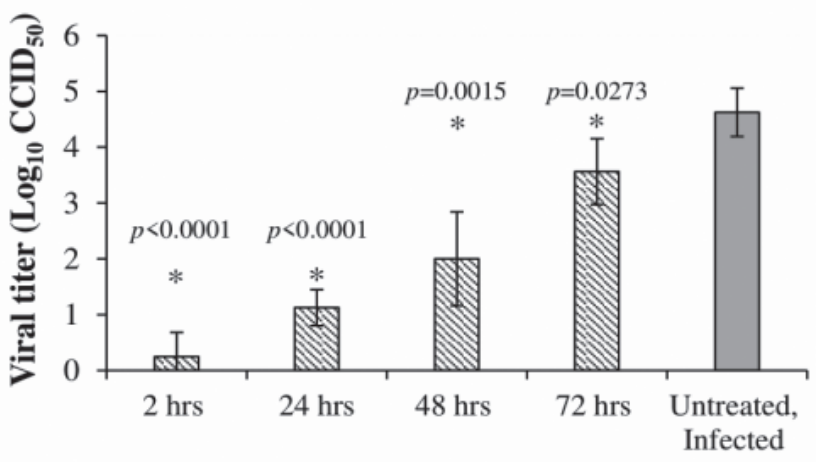

Treatment timepoint post-infection (hpi)

\section{C) CV-A10}

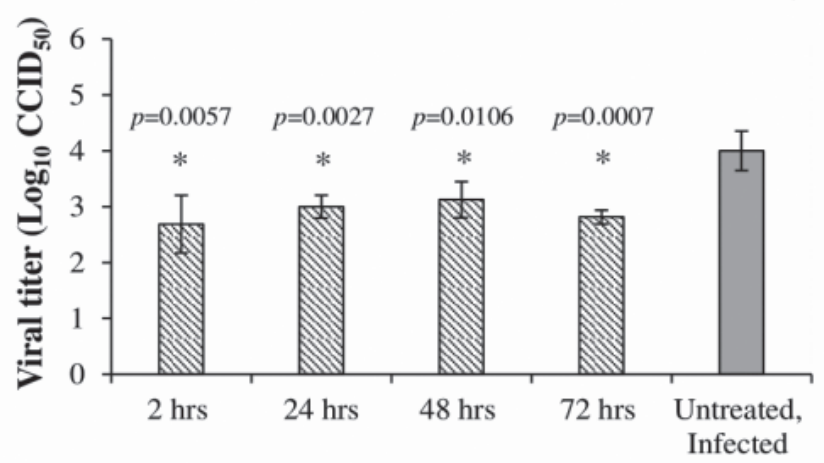

Treatment timepoint post-infection (hpi)
D) CV-A6

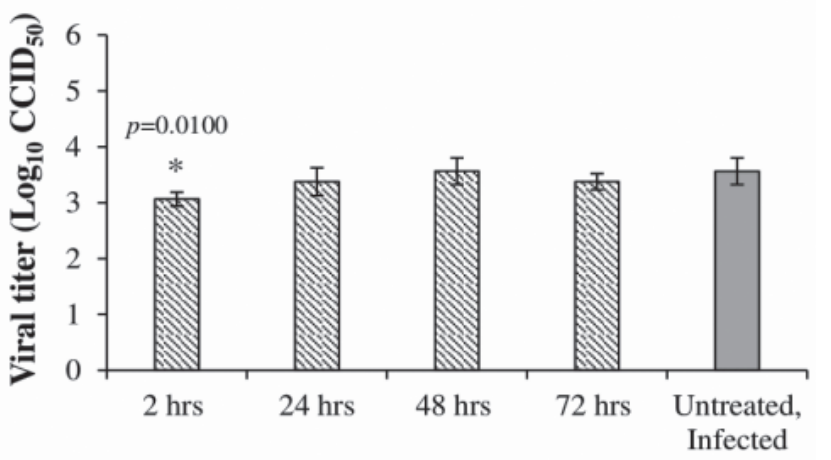

Treatment timepoint post-infection (hpi)

\section{Treated, Infected}

Figure 3. Post-infection treatment efficacy of $S 2$ against A) EV-A71, B) CV-A16, C) CV-A10 and D) CV-A6. From 2 hpi to 72 hpi, significantly lower virus titers were shown in EV-A71, CV-A16 and CV-A10 infected cells treated with S2. CV-A6 virus titer was only significantly lower at $2 \mathrm{hpi}$. Virus titers were expressed as the mean $\log _{10} \mathrm{CCID}_{50} \pm$ standard deviation. ${ }^{*}=$ statistically significant $(p<0.05)$.

A16-S2 mixtures (4.5 $\left.\log _{10} \mathrm{CCID}_{50} \pm 0.408, p=0.648\right)$ (Figure $\left.2 \mathrm{~B}\right)$, CV-A10-S2 mixtures (3.81 $\log _{10} \mathrm{CCID}_{50} \pm 0.239, p=0.1135$ ) (Figure $2 \mathrm{C})$ and CV-A6-S2 mixtures (4 $\left.\log _{10} \mathrm{CCID}_{50} \pm 0.354, p=0.1466\right)$ (Figure 2D) compared to virus-DMEM infected controls $(4.38$ $\log _{10} \mathrm{CCID}_{50} \pm 0.323,3.56 \log _{10} \mathrm{CCID}_{50} \pm 0.125$ and $3.69 \log _{10}$ $\mathrm{CCID}_{50} \pm 0.125$, respectively).

Post-infection treatment efficacy of S2 against EV-A71, CV-A16, CV-A10 and CV-A6 replication

To further evaluate the post-infection treatment efficacy, EVA71, CV-A16, CV-A10 and CV-A6 infected HPOF cells were treated with S2 at various hpi. The virus titers of EV-A71, CV$A 16$ and $C V-10$ were significantly lowered at all time points (Figure 3A, 3B, 3C). However, virus titer of CV-A6 was only significantly reduced at 2 hpi (Figure 3D).

\section{Antiviral activity of GNJI polysaccharides}

HPOF cells infected with EV-A71 and CV-A16 were treated with $1.25 \mathrm{mg} / \mathrm{ml}$ of $\mathrm{S} 5$ at various hpi similarly as described in the post-infection treatment experiment. The virus titers of EVA71 were significantly lowered at 2 hpi to 48 hpi (Figure 4 A), while virus titers of CV-A16 were significantly reduced at all treatment time points (Figure 4B). Besides, S5 also demonstrated virucidal effect against cell-free EV-A71. Cells inoculated with EV-A71-S5 mixtures have significantly lower virus titers (3.56 $\left.\log _{10} \mathrm{CCID}_{50} \pm 0.375, p=0.0175\right)$ compared to virus-DMEM infected control (4.13 $\left.\log _{10} C_{C C I} D_{50} \pm 0.144\right)$ (Figure 5). No cytotoxic effect was observed in S5 treated, uninfected HPOF cells (data not shown).

\section{DISCUSSION}

Developing a safe and effective antiviral agent for HFMD is challenging as the disease could be caused by multiple etiological agents (Klein \& Chong, 2015; Wang et al., 2017). To date, the research and development of antiviral agents are mainly focused on EV-A71 (Lei et al., 2015) even though CV-A10 and CV-A6 associated HFMD are on the rise not only in AsiaPacific countries but worldwide (Bian et al., 2015; Bian et al., 2019). Most likely, these emerging HFMD viruses could potentially become the dominant serotypes. A narrowspectrum antiviral agent will only be beneficial to a small portion of HFMD patients. Hence, this highlighted the importance of developing a broad-spectrum antiviral agent against common and emerging enteroviruses that caused HFMD.

In this study, we have investigated the in vitro antiviral activity of GNJI crude extracts obtained from different preparation methods (see Materials and Methods) against 4 HFMD enteroviruses. To our knowledge, this study appears 


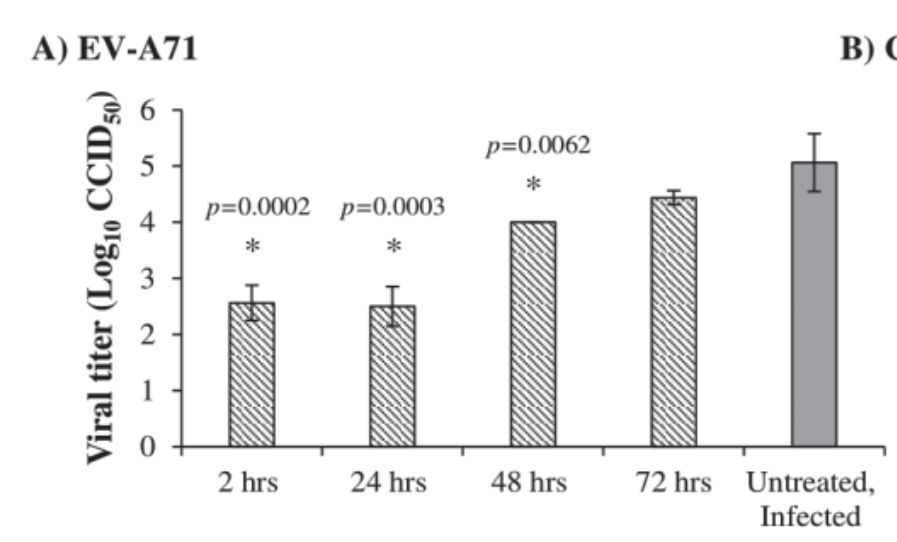

Treatment timepoint post-infection (hpi)
B) CV-A16

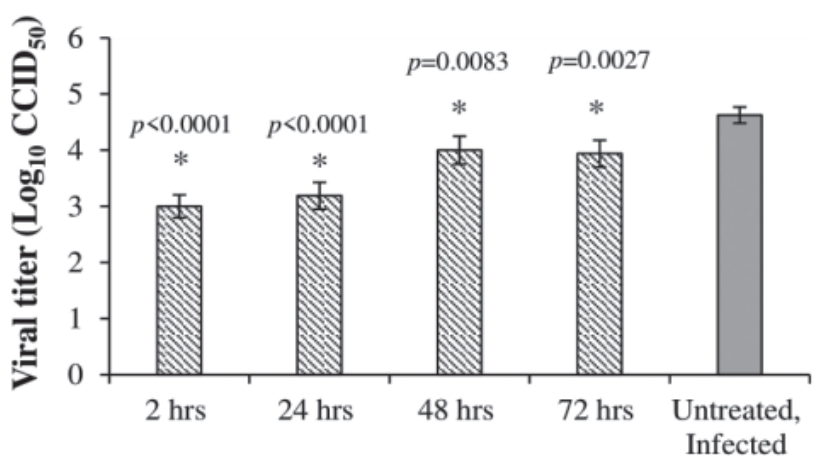

Treatment timepoint post-infection (hpi)

\section{Treated, Infected}

Figure 4. Post-infection treatment efficacy of S5 against A) EV-A71 and B) CV-A16. The virus titers of EV-A71 infected cells treated with S5 at $2 \mathrm{hpi}$ to $48 \mathrm{hpi}$ were significantly lower than untreated control. CV-A16 virus titer was significantly lower at all time points. Virus titers were expressed as the mean $\log _{10} \mathrm{CCID}_{50} \pm$ standard deviation. ${ }^{*}=$ statistically significant $(p<0.05)$.

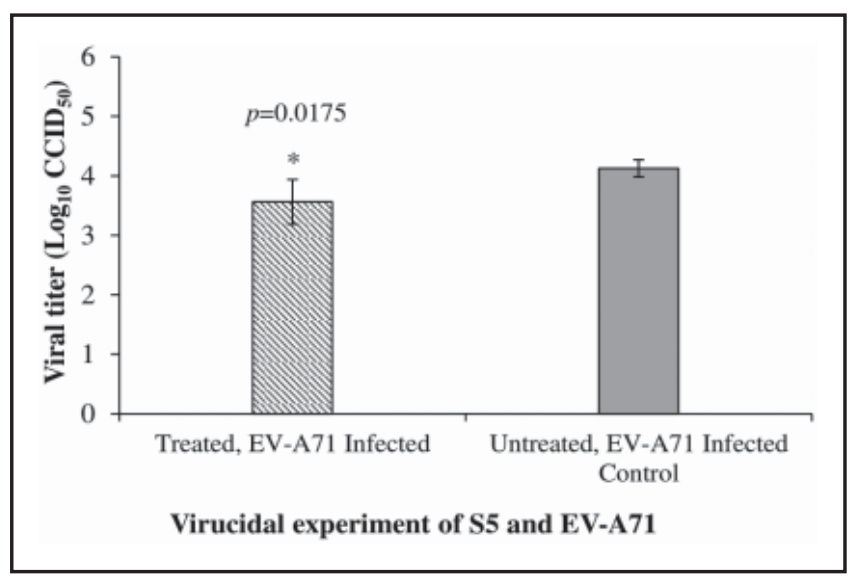

Figure 5. Virucidal activity of S5 against EV-A71. S5 demonstrated virucidal activity against EV-A71. Virus titers were expressed as the mean $\log _{10} \mathrm{CCID}_{50} \pm$ standard deviation. * = statistically significant.

to be the first study investigating the antiviral activity of GNJI mushroom against enteroviruses.

As demonstrated in the post-infection treatment experiment, S2 was highly effective in inhibiting EV-A71, CVA16 and CV-A10 replication, even when the infected cells were treated at a late time point (72 hpi). However, S2 was less effective in inhibiting CV-A6 replication. CV-A6 may be able to overcome the antiviral effects of S2 better than the other three enteroviruses, leading to higher viral titers. However, the exact mechanism is unknown and required further investigations to explain the differences observed in our study. As shown in the virucidal experiment, S2 demonstrated virucidal activity against EV-A71 but not to other enteroviruses. We hypothesized that this could be due to the structural differences between EV-A71 virion and other enteroviruses as reported previously (Ren et al., 2015; Chen et al., 2018; Chen et al., 2019). Despite demonstrating good antiviral activities in the post-infection treatment and virucidal experiments, no antiviral activity was detected in the pre-infection treatment experiment, suggesting that $\mathrm{S} 2$ could not serve as a prophylaxis agent to prevent EV-A71, CVA16, CV-A10 and CV-A6 infection. This result also further implied that virucidal effect of S2 against EV-A71 may not be related to the interaction between $\mathrm{S} 2$ and the cells, instead, directly with the EV-A71 virus particle itself.

The different antiviral spectrum observed between the crude extracts (S1-S4) could be attributed to the different extraction methods used (extraction solvent, boiling duration, etc.) (Zhang et al., 2007; Subramaniam et al., 2014). S2 possesses the broadest antiviral spectrum, suggesting that the antiviral bioactive compounds may have a higher solubility in water than in organic solvent. Hot water extraction is regarded as a common and simple method to extract water-soluble polysaccharides from Ganoderma mushrooms (Ling-Sing Seow et al., 2013; Nie et al., 2013; Ferreira et al., 2015; Zhu et al., 2015; Gong et al., 2020). In addition, the antiviral bioactive compounds present in S2 appear to be thermally stable and were not negatively affected during the heating process as demonstrated by the results. However, whether or not this hot water extraction method will negatively affect other non-antiviral compounds requires further investigations.

The prolonged boiling ( 30 mins vs $3 \mathrm{hrs}$ ) may enhance the destruction of fungal cell wall and its subcellular compartment, which will therefore increase the release of water-soluble bioactive compounds such as polysaccharides that are found in abundance in fungal cell wall (Zhang et al., 2007; Rop et al., 2009). We speculate that the amount and proportion of the extracted antiviral bioactive compound may be relatively lower in S1 as compared to S2. Polysaccharides extracted from G.lucidum and G.pfeifferi were previously found to exhibit antiviral activities against herpes simplex virus (Hassan et al., 2015) and influenza virus type A (Mothana et al., 2003), respectively. Similarly, the polysaccharides isolated from GNJI (S5) was found to be able to inhibit the replication of EV-A71 and CV-A16 when treated at later time points postinfection. S5 also demonstrated virucidal activity against EVA71. These results further suggested that polysaccharides could be one of the active components presents in S2. Although there was a slight difference in the boiling duration 
between S5 and S2, it is predicted that S2 would contain polysaccharides as well since both were extracted using the same method. S5 was previously shown to contain $\beta$-glucan rich polysaccharides (39.26 mg/100 mg; w/w) (Subramaniam et al., 2017). Hence, $\beta$-glucan rich polysaccharides may be one of the vital bioactive compounds responsible for the antiviral activity seen in this study.

Besides polysaccharides, triterpenoids are also the common constituent of Ganoderma mushrooms (Chen et al., 2015; Hapuarachchi et al., 2017). Triterpenoids isolated from G.lucidum have previously demonstrated virucidal activity against EV-A71 infection in RD cells (Zhang et al., 2014). We postulate that the virucidal activity of $\mathrm{S} 2$ could be due to the presence of triterpenoids as well. Both polysaccharides and triterpenoids could be part of the constituents of S2 and therefore contributing to its antiviral activity. The speculated bioactive compounds in S2 were not identified or quantified. Thus, further characterization S2 is needed to confirm these speculations.

Although numerous natural compounds have been reported to contain antiviral activity against EV-A71, none of these compounds have demonstrated broad-spectrum antiviral activities against CV-A16, CV-A10 and CV-A6 (Ji et al., 2015; Zhao et al., 2016). Nonetheless, it has to be addressed that further investigations are necessary to reveal the exact mechanism of antiviral action of S2. The current in vitro findings are preliminary and further validation by animal studies are essential to provide more profound insights into the efficacy of this extract in ameliorating the disease and its complications as well.

In conclusion, our findings demonstrated that GNJI S2 aqueous extract is a candidate to be further characterized and developed into an effective, safe and broad-spectrum antiviral agent against enteroviruses that caused HFMD and possibly other medically important human viruses as well.

\section{ACKNOWLEDGEMENTS}

This study was supported by the Fundamental Research Grant Scheme from the Malaysian Government, Ministry of Higher Education (FP038/2015A; UM.0000312/HME.FS) and Jo Li Trust UK (IF046-2018; UM.0000176/HIF.IF).

\section{Conflict of interests}

The authors declared no conflict of interests.

\section{REFERENCES}

Anh, N.T., Nhu, L.N.T., Van, H.M.T., Hong, N.T.T., Thanh, T.T., Hang, V.T.T., Ny, N.T.H., Nguyet, L.A., Phuong, T.T.L. \& Nhan, L.N.T. (2018). Emerging coxsackievirus A6 causing hand, foot and mouth disease, Vietnam. Emerging Infectious Diseases 24: 654-662. https://doi.org/10.3201/eid2404. 171298

Baby, S., Johnson, A.J. \& Govindan, B. (2015). Secondary metabolites from Ganoderma. Phytochemistry 114: 66-101. https://doi.org/10.1016/j.phytochem.2015.03.010

Bian, L., Gao, F., Mao, Q., Sun, S., Wu, X., Liu, S., Yang, X. \& Liang, Z. (2019). Hand, foot, and mouth disease associated with coxsackievirus A10: more serious than it seems. Expert Review of Anti-infective Theraphy 17: 233-242. https://doi.org/ 10.1080/14787210.2019.1585242

Bian, L., Wang, Y., Yao, X., Mao, Q., Xu, M. \& Liang, Z. (2015). Coxsackievirus A6: a new emerging pathogen causing hand, foot and mouth disease outbreaks worldwide. Expert Review of Anti-infective Theraphy 13: 1061-1071. https://doi.org/10.1586/14787210.2015.1058156
Blomqvist, S., Klemola, P., Kaijalainen, S., Paananen, A., Simonen, M.L., Vuorinen, T. \& Roivainen, M. (2010). Cocirculation of coxsackieviruses $A 6$ and $A 10$ in hand, foot and mouth disease outbreak in Finland. Journal of Clinical Virology 48: 49-54. https://doi.org/10.1016/j.jcv.2010.02.002

Bracho, M.A., Gonzalez-Candelas, F., Valero, A., Cordoba, J. \& Salazar, A. (2011). Enterovirus co-infections and onychomadesis after hand, foot, and mouth disease, Spain, 2008. Emerging Infectious Diseases 17: 2223-2231. https://doi.org/10.3201/eid1712.110395

Chen, J., Ye, X., Zhang, X.Y., Zhu, Z., Zhang, X., Xu, Z., Ding, Z., Zou, G., Liu, Q. \& Kong, L. (2019). Coxsackievirus A10 atomic structure facilitating the discovery of a broad-spectrum inhibitor against human enteroviruses. Cell Discovery 5: 4. https://doi.org/10.1038/s41421-018-0073-7

Chen, J., Zhang, C., Zhou, Y., Zhang, X., Shen, C., Ye, X., Jiang, W., Huang, Z. \& Cong, Y. (2018). A 3.0-Angstrom resolution cryoelectron microscopy structure and antigenic sites of coxsackievirus A6-Like particles. Journal of Virology 92. https://doi.org/10.1128/JVI.01257-17

Chen, M., He, S., Yan, Q., Xu, X., Wu, W., Ge, S., Zhang, S., Chen, M. \& Xia, N. (2017). Severe hand, foot and mouth disease associated with coxsackievirus A10 infections in Xiamen, China in 2015. Journal of Clinical Virology 93: 20-24. https:// doi.org/10.1016/j.jcv.2017.05.011

Chen, M.L., Hsieh, C.C., Chiang, B.L. \& Lin, B.F. (2015). Triterpenoids and polysaccharide fractions of Ganoderma tsugae exert different effects on antiallergic activities. Evidence-Based Complementary and Alternative Medicine 2015: 754836. https://doi.org/10.1155/2015/754836

Cisterna, D.M., Lema, C.L., Martinez, L.M., Veron, E., Contarino, L.P., Acosta, D. \& Freire, M.C. (2019). Atypical hand, foot, and mouth disease caused by Coxsackievirus $A 6$ in Argentina in 2015. Revista Argentina de Microbiologia 51: 140-143. https://doi.org/10.1016/j.ram.2018.05.003

Ferreira, I.C., Heleno, S.A., Reis, F.S., Stojkovic, D., Queiroz, M.J., Vasconcelos, M.H. \& Sokovic, M. (2015). Chemical features of Ganoderma polysaccharides with antioxidant, antitumor and antimicrobial activities. Phytochemistry 114: 38-55. https://doi.org/10.1016/j.phytochem.2014.10.011

Gong, P., Wang, S., Liu, M., Chen, F., Yang, W., Chang, X., Liu, N., Zhao, Y., Wang, J. \& Chen, X. (2020). Extraction methods, chemical characterizations and biological activities of mushroom polysaccharides: A mini-review. Carbohydrate Research 494: 108037. https://10.1016/j.carres.2020.108037

Hapuarachchi, K., Cheng, C., Wen, T., Jeewon, R. \& Kakumyan, P. (2017). Mycosphere essays 20: therapeutic potential of Ganoderma species: Insights into its use as traditional medicine. Mycosphere 8: 1653-1694. https://doi.org/10.5943/ mycosphere $/ 8 / 10 / 5$

Hassan, S.T., Masarcikova, R. \& Berchova, K. (2015). Bioactive natural products with anti-herpes simplex virus properties. Journal of Pharmacy and Pharmacology 67: 1325-1336. https://doi.org/10.1111/jphp.12436

Huang, W.C., Chang, M.S., Huang, S.Y., Tsai, C.J., Kuo, P.H., Chang, H.W., Huang, S.T., Kuo, C.L., Lee, S.L. \& Kao, M.C. (2019). Chinese herbal medicine Ganoderma tsugae displays potential anti-cancer efficacy on metastatic prostate cancer cells. International Journal of Molecular Sciences 20. https://doi.org/10.3390/ijms20184418

Ji, P., Chen, C., Hu, Y., Zhan, Z., Pan, W., Li, R., Li, E., Ge, H.M. \& Yang, G. (2015). Antiviral activity of Paulownia tomentosa against enterovirus 71 of hand, foot, and mouth disease. Biological and Pharmaceutical Bulletin 38: 1-6. https://doi.org/ 10.1248/bpb.b14-00357 
Justino, M.C.A., da, S.M.D., Souza, M.F., Farias, F.P., Dos, S.A.J.C., Ferreira, J.L., Lopes, D.P. \& Tavares, F.N. (2020). Atypical hand-foot-mouth disease in Belem, Amazon region, northern Brazil, with detection of coxsackievirus A6. Journal of Clinical Virology 126: 104307. https://doi.org/ 10.1016/j.jcv.2020.104307

Karber, G. (1931). 50\% end point calculation. Archiv fur Experimentelle Pathologie und Pharmakologie 162: 480-483.

Klein, M. \& Chong, P. (2015). Is a multivalent hand, foot, and mouth disease vaccine feasible? Human vaccines \& immunotherapeutics 11: 2688-2704. https://doi.org/10.1080/ 21645515.2015.1049780

Lei, X., Cui, S., Zhao, Z. \& Wang, J. (2015). Etiology, pathogenesis, antivirals and vaccines of hand, foot, and mouth disease. National Science Review 2: 268-284. https://doi.org/10.1093/ nsr/nwv038

Li, Y., Yang, Y., Fang, L., Zhang, Z., Jin, J. \& Zhang, K. (2006). Antihepatitis activities in the broth of Ganoderma lucidum supplemented with a chinese herbal medicine. The American Journal of Chinese Medicine 34: 341-349. https:// doi.org/10.1142/S0192415X06003874

Lin, J.Y., Kung, Y.A. \& Shih, S.R. (2019). Antivirals and vaccines for Enterovirus A71. Journal of Biomedical Science 26: 65. https://doi.org/10.1186/s12929-019-0560-7

Linden, L., Wolthers, K. \& van Kuppeveld, F. (2015). Replication and inhibitors of enteroviruses and parechoviruses. Viruses 7: 4529-4562. https://doi.org/10.3390/v7082832

Ling-Sing Seow, S., Naidu, M., David, P., Wong, K.H. \& Sabaratnam, V. (2013). Potentiation of neuritogenic activity of medicinal mushrooms in rat pheochromocytoma cells. BMC Complementary and Alternative Medicine 13: 157. https://doi.org/10.1186/1472-6882-13-157

Liu, W., Wu, S., Xiong, Y., Li, T., Wen, Z., Yan, M., Qin, K., Liu, Y. \& Wu, J. (2014). Co-circulation and genomic recombination of coxsackievirus A16 and enterovirus 71 during a large outbreak of hand, foot, and mouth disease in Central China. PLoS One 9: e96051. https://doi.org/10.1371/journal. pone.0096051

Lizasoain, A., Piegas, S., Victoria, M., Da Silva, E.E. \& Colina, R. (2020). Hand-foot-and-mouth disease in uruguay: Coxsackievirus A6 identified as causative of an outbreak in a rural childcare center. Journal of Medical Virology 92: 167173. https://doi.org/10.1002/jmv. 25590

Mirand, A., Henquell, C., Archimbaud, C., Ughetto, S., Antona, D., Bailly, J.L. \& Peigue-Lafeuille, H. (2012). Outbreak of hand, foot and mouth disease/herpangina associated with coxsackievirus $A 6$ and $A 10$ infections in 2010, France: a large citywide, prospective observational study. Clinical Microbiology and Infection 18: E110-118. https://doi.org/ 10.1111/j.1469-0691.2012.03789.x

Mothana, R.A., Awadh Ali, N.A., Jansen, R., Wegner, U., Mentel, R. \& Lindequist, U. (2003). Antiviral lanostanoid triterpenes from the fungus Ganoderma pfeifferi. Fitoterapia 74: 177180. https://doi.org/10.1016/s0367-326x(02)00305-2

Nie, S., Zhang, H., Li, W. \& Xie, M. (2013). Current development of polysaccharides from Ganoderma: isolation, structure and bioactivities. Bioactive Carbohydrates and Dietary Fibre 1: 10-20. https://doi.org/10.1016/j.bcdf.2013.01.001

Ong, K.C., Badmanathan, M., Devi, S., Leong, K.L., Cardosa, M.J. \& Wong, K.T. (2008). Pathologic characterization of a murine model of human enterovirus 71 encephalomyelitis. Journal of Neuropathology and Experimental Neurology 67: 532-542. https://doi.org/10.1097/NEN.0b013e31817713e7
Phyu, W.K., Ong, K.C., Kong, C.K., Alizan, A.K., Ramanujam, T.M. \& Wong, K.T. (2017). Squamous epitheliotropism of enterovirus $A 71$ in human epidermis and oral mucosa. Scientific Reports 7: 45069. https://doi.org/10.1038/srep45069

Ren, J., Wang, X., Zhu, L., Hu, Z., Gao, Q., Yang, P., Li, X., Wang, J., Shen, X. \& Fry, E.E. (2015). Structures of coxsackievirus A16 capsids with native antigenicity: Implications for particle expansion, receptor binding, and immunogenicity. Journal of Virology 89: 10500-10511. https://doi.org/10.1128/ JVI.01102-15

Repass, G.L., Palmer, W.C. \& Stancampiano, F.F. (2014). Hand, foot, and mouth disease: identifying and managing an acute viral syndrome. Cleveland Clinical Journal of Medicine 81: 537-543. https://doi.org/10.3949/ccjm.81a.13132

Rop, O., Mlcek, J. \& Jurikova, T. (2009). Beta-glucans in higher fungi and their health effects. Nutrition Reviews 67: 624631. https://10.1111/j.1753-4887.2009.00230.x

Sliva, D. (2003). Ganoderma lucidum (Reishi) in cancer treatment. Integrative Cancer Therapies 2: 358-364. https:// doi.org/10.1177/1534735403259066

Stewart, C.L., Chu, E.Y., Introcaso, C.E., Schaffer, A. \& James, W.D. (2013). Coxsackievirus A6-induced hand-foot-mouth disease. JAMA Dermatology 149: 1419-1421. https://doi.org/ 10.1001/jamadermatol.2013.6777

Subramaniam, S., Raman, J., Sabaratnam, V., Heng, C.K. \& Kuppusamy, U.R. (2017). Functional properties of partially characterized polysaccharide from the medicinal mushroom Ganoderma neo-japonicum (Agaricomycetes). International Journal of Medicinal Mushrooms 19: 849-859. https://doi.org/10.1615/IntJMedMushrooms.2017024355

Subramaniam, S., Sabaratnam, V., Chua, K.H. \& Kuppusamy, U.R. (2020). The medicinal mushroom Ganoderma neojaponicum (Agaricomycetes) from Malaysia: Nutritionalc and potentiation of insulin-like activity in 3T3-L1 cells. International Journal of Medicinal Mushrooms 22. https:// doi.org/10.1615/intjmedmushrooms.2020033250

Subramaniam, S., Sabaratnam, V., Kuppusamy, U.R. \& Tan, Y.S. (2014). Solid-substrate fermentation of wheat grains by mycelia of indigenous species of the genus Ganoderma (higher Basidiomycetes) to enhance the antioxidant activities. International journal of medicinal mushrooms 16: 259-267. https://doi.org/10.1615/intjmedmushr.v16.i3.60

Tan, W.C., Kuppusamy, U.R., Phan, C.W., Tan, Y.S., Raman, J., Anuar, A.M. \& Sabaratnam, V. (2015). Ganoderma neojaponicum Imazeki revisited: domestication study and antioxidant properties of its basidiocarps and mycelia. Scientific Reports 5: 12515. https://doi.org/10.1038/srep12515

Tan, Y.W. \& Chu, J.J.H. (2017). Sinovac EV71 vaccine: the silver bullet for hand, foot and mouth disease or not? Journal of Public Health and Emergency 1. http://dx.doi.org/10.21037/ jphe.2016.12.14

Wang, J., Hu, T., Sun, D., Ding, S., Carr, M.J., Xing, W., Li, S., Wang, X. \& Shi, W. (2017). Epidemiological characteristics of hand, foot, and mouth disease in Shandong, China, 2009-2016. Scientific Reports 7: 8900. https://doi.org/10.1038/ s41598-017-09196-z

Wei, S.H., Huang, Y.P., Liu, M.C., Tsou, T.P., Lin, H.C., Lin, T.L., Tsai, C.Y., Chao, Y.N., Chang, L.Y. \& Hsu, C.M. (2011). An outbreak of coxsackievirus $A 6$ hand, foot, and mouth disease associated with onychomadesis in Taiwan, 2010. BMC Infectious Diseases 11: 346. https://doi.org/10.1186/ 1471-2334-11-346 
Wu, Y., Yeo, A., Phoon, M.C., Tan, E.L., Poh, C.L., Quak, S.H. \& Chow, V.T. (2010). The largest outbreak of hand; foot and mouth disease in Singapore in 2008: the role of enterovirus 71 and coxsackievirus A strains. International Journal of Infectious Diseases 14: e1076-1081. https://doi.org/ 10.1016/j.ijid.2010.07.006

Zhang, M., Cui, S., Cheung, P. \& Wang, Q. (2007). Antitumor polysaccharides from mushrooms: a review on their isolation process, structural characteristics and antitumor activity. Trends in Food Science \& Technology 18: 4-19. https://doi.org/10.1016/j.tifs.2006.07.013

Zhang, W., Tao, J., Yang, X., Yang, Z., Zhang, L., Liu, H., Wu, K. \& Wu, J. (2014). Antiviral effects of two Ganoderma lucidum triterpenoids against enterovirus 71 infection. Biochemical and Biophysical Research Communications 449: 307-312. https:/ /doi.org/10.1016/j.bbrc.2014.05.019
Zhao, C., Gao, L., Wang, C., Liu, B., Jin, Y. \& Xing, Z. (2016). Structural characterization and antiviral activity of a novel heteropolysaccharide isolated from Grifola frondosa against enterovirus 71. Carbohydrate Polymers 144: 382-389. https://doi.org/10.1016/j.carbpol.2015.12.005

Zhu, F., Du, B. \& Xu, B. (2015). Preparation and characterization of polysaccharides from mushrooms. Polysaccharides: Bioactivity and Biotechnology 1009-1027. https://doi.org/ 10.1007/978-3-319-03751-6_10-1 